\title{
The impact of the Malaysian minimum cigarette price law: findings from the ITC Malaysia Survey
}

\author{
Alex C Liber, ${ }_{1}^{1}$ Hana Ross, ${ }^{2}$ Maizurah Omar, ${ }^{3}$ Frank J Chaloupka ${ }^{4,5,6}$
}

- Additional material is published online only. To view please visit the journal online (http://dx.doi.org/10.1136/ tobaccocontrol-2014-052028).

${ }^{1}$ Economic and Health Policy Research, Intramural Research, American Cancer Society Inc., Atlanta, Georgia, USA ${ }^{2}$ SALDRU Research Affiliate, University of Cape Town, Cape Town, South Africa

${ }^{3}$ Clearinghouse for Tobacco

Control, National Poison

Centre, Universiti Sains, Pulau

Penang, Malaysia

${ }^{4}$ Department of Economics, Institute for Health Research and Policy, University of Illinois at Chicago, Chicago, Illinois, USA

${ }^{5}$ Health Policy Center, Institute for Health Research and Policy, University of Illinois at Chicago, Chicago, Illinois, USA ${ }^{6}$ WHO Collaborating Centre on the Economics of Tobacco and Tobacco Control

\section{Correspondence to}

Alex C Liber, Economic and Health Policy Research, Intramural Research, American Cancer Society Inc., Atlanta GA 30303, USA:

alex.liber@cancer.org.

Received 15 September 2014 Accepted 3 March 2015

Published Online First 25 March 2015

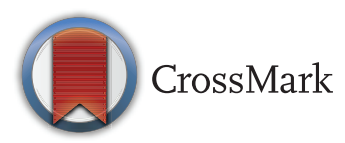

To cite: Liber AC, Ross $\mathrm{H}$ Omar $\mathrm{M}$, et al. Tob Control 2015;24:iii83-iii87.

\section{ABSTRACT}

Objectives Study the effects of the 2011 Malaysian minimum price law (MPL) on prices of licit and illicit cigarette brands. Identify barriers to the MPL achieving positive public health effects.

Methods The International Tobacco Control Project's Southeast Asia survey collected information on Malaysian smokers' cigarette purchases $(n=7520)$ in five survey waves between 2005 and 2012. Consumption-weighted comparisons of proportions tests and adjusted Wald tests were used to evaluate changes over time in violation rates of the inflation-adjusted MPL, the proportion of illicit cigarette purchases and mean prices.

Results After the passage of the MPL, the proportion of licit brand cigarette purchases that were below the inflation-adjusted 2011 minimum price level fell substantially (before $3.9 \%$, after $1.8 \%, p=0.002$ ), while violation of the MPL for illicit brand cigarette purchases was unchanged (before 89.8\%, after 91.9\%, $p=0.496$ ). At the same time, the mean real price of licit cigarettes rose $(p=0.006)$, while the mean real price of illicit cigarettes remained unchanged $(p=0.134)$. The proportion of illicit cigarette purchases rose as well (before $13.4 \%$, after $16.5 \%, p=0.041$ ).

Discussion The MPL appears not to have meaningfully changed cigarette prices in Malaysia, as licit brand prices remained well above and illicit brand prices remained well below the minimum price level before and after MPL's implementation. The increasing proportion of illicit cigarettes on the market may have undermined any positive health effects of the Malaysian MPL. The illicit cigarette trade must be addressed before a full evaluation of the Malaysian MPL's impact on public health can take place. The authors encourage the continued use of specific excise tax increases to reliably increase the price and decrease the consumption of cigarettes in Malaysia and elsewhere.

\section{INTRODUCTION}

Raising cigarette taxes is one of the most effective tobacco control measures available to policymakers. ${ }^{1}{ }^{2}$ Regular, substantial price increases reduce tobacco consumption and related morbidity and mortality. ${ }^{3}{ }^{4}$ Beyond raising tax rates, there are other policy options available to regulate the prices of cigarettes, including banning price promotions and discounts, establishing a minimum retail price or a minimum tax rate, implementing minimum packaging sizes, banning the sale of individual cigarettes, and raising retail prices by at least the full amount of an excise tax increase. ${ }^{5} 6$ The public health logic behind adopting such policies is to eliminate inexpensive tobacco products, so that particularly the young and the poor, the two most vulnerable groups when it comes to tobacco use, will be discouraged from purchasing cigarettes and will consequentially reduce their cigarette consumption or not initiate smoking. ${ }^{6}$ In some cases, an additional intention of these laws is to protect retailers from manufacturers' pressure to lower prices at the expense of retailers' profits. ${ }^{7}$ Recently, several European Union countries enacted minimum price laws (MPLs) for cigarettes to protect public health, but these policies were nullified in 2010 when the European Court of Justice ruled that Ireland's MPL was an anticompetitive practice, and subsequently struck it down. ${ }^{8}$ On the other hand, there are cases (eg, in Ecuador) when the tobacco industry itself proposed the adoption of an MPL, which would have likely protected incumbent firms' market shares from potential competitors who could enter the market with cheaper products. ${ }^{9}$

Malaysia adopted its own MPL in January 2010, setting the minimum retail price at 0.32 Ringgit (MYR; US\$0.09) per cigarette, or MYR6.40 (US $\$ 1.88$ ) per 20-stick pack. $^{10}$ The Malaysian Parliament passed the $2010 \mathrm{MPL}$ in conjunction with a ban on selling cigarettes in packs of less than 20 sticks (so-called 'kiddie packs') and a ban on price promotions for tobacco products (eg, couponing and bulk purchase discounts). ${ }^{10}$ In April 2011, the Parliament raised the minimum price further to MYR0.35 per cigarette, or MYR7.00 (US\$2.31) per 20 -stick pack. ${ }^{11}$ The MPL applies only to machinemade cigarettes and does not apply to roll-your-own tobacco products. The objectives of the Malaysian MPL were twofold: (1) to address the affordability of cigarettes, especially to lower income persons and youths; and (2) to prevent the local tobacco industry from conducting price promotion (discounting) exercises. The Confederation of Malaysian Tobacco Manufacturers, representing the Malaysian subsidiaries of British American Tobacco, Philip Morris International and Japan Tobacco International, publicly supports the MPL's strong enforcement. $^{12}$

In $2013,37.9 \%$ of men and $1.5 \%$ of women in Malaysia smoked cigarettes, figures that have not significantly changed since at least $1980 .{ }^{13}$ A sizeable proportion of cigarettes consumed in Malaysia (greater than $15 \%$ of the market) are sourced from illicit channels and do not bear legal tax stamps (because Malaysian excise taxes have not been paid on the products) or warning labels on purchased packs. ${ }^{14}{ }^{15}$ Malaysia employs a mixed tobacco excise tax system consisting of an ad-valorem component (equal to $25 \%$ of the tax-inclusive price) that remained unchanged over the course of the study period, and a specific component. The specific tax's share of the retail price was almost triple the ad-valorem tax's share of the retail price of 
premium cigarettes in 2013 (43\% vs 14\%), which means that the specific component was the dominant factor responsible for price changes in the Malaysia market, especially in the later years of our study period. ${ }^{16}$ The adoption of the MPL occurred in the midst of a series of specific excise tax increases between 2005 and 2010 that more than doubled the nominal specific tax on cigarettes. ${ }^{16-18}$ As a function of price and income, cigarettes became more affordable in Malaysia between 1990 and 2006, but the aforementioned series of excise tax increases kept cigarette affordability at a consistent level, while incomes in the country grew between 2006 and 2012. ${ }^{19-21}$ To aid visualisation, figure 1 plots policy changes over the course of the study period.

No prior study has tried to examine how the MPL has affected the Malaysian cigarette market. In this article, we examine the prices that smokers paid for their licit and illicit brand cigarettes before and after the MPL came into effect.

\section{DATA AND METHODS}

We used data from the first five waves of the International Tobacco Control (ITC) Project's Surveys in Malaysia, which were conducted between January 2005 and March 2012 (individual survey duration periods are also plotted in figure 1). The surveys collected information from a nationally representative longitudinal sample, which added replacement respondents for those lost to follow-up, of current and former adult smokers from 7 of 14 Malaysian states (13 states plus 1 Federal Territory). Interviews were conducted both face-to-face (waves 1 through 3) and over the telephone (waves 2 through 5). The survey methods are described in greater detail by Yong et $a l^{22}$ and the ITC Project. ${ }^{23}{ }^{24}$ We used information about a survey respondent's last cigarette purchase, including the price paid (in local currency), packaging (cartons, packs or single sticks), quantity (number of sticks per purchase) and brand in order to standardise purchases in different quantities to be equivalent to the price paid for a standard pack of 20 cigarettes. We excluded former smokers from our sample because those persons' last cigarette purchase would not have occurred in the near past. Local currency units are used to report both the nominal and real prices (indexed for inflation on a monthly basis to January 2011). ${ }^{25}$ Illicit cigarettes are substantially less expensive than licit cigarettes because excise taxes are not paid on the product, and in recognition of this prominent determinant of cigarette purchase price, we classified cigarette brands as either licit or illicit based on whether a brand was known to be sold primarily through illegal channels, as reported in the scientific literature and the industry's data. ${ }^{26} 27$

Our study examines whether the MPL changed consumers' decisions on prices paid in the Malaysian cigarette market. We measure rates of violation of the inflation-adjusted $2011 \mathrm{MPL}$ of MYR7.00 by cigarette retailers (ie, the party tasked with establishing the final price at which a cigarette is sold) through an examination of the self-reported purchase prices of smokers. Changes in the mean prices and MPL violation rates of both licit and illicit cigarettes, as well as the proportion of illicit cigarette purchases are studied over time, paying particular attention to changes between wave 4 (July 2009-November 2009) and wave 5 (May 2011-March 2012), which attempts to capture the short-term impact of both the MYR6.40 and MYR7.00 MPL. We cannot disentangle the effect of the higher, second MPL from the first because we do not have data from the period when the first MPL was in effect, but before the second MPL was implemented. Adjusted Wald tests were used to evaluate changes in mean prices, while comparisons of proportions tests evaluated changes in violation rates with the inflation-adjusted 2011 minimum price level from one survey wave to the next. Consumption weights were created as the ratio of the number of cigarettes consumed daily by a survey respondent to the total daily cigarette consumption of the entire sample in each wave, and employed in our analyses in order to take into account brand choice and consumption patterns of consumers. ${ }^{28}$ Separate mean prices, MPL violation rates and proportions of illicit cigarette purchases were calculated for each brand group and packaging type for each survey wave.

After eliminating observations that contained missing values or recorded purchases of cartons (which contained an indeterminate number of cigarettes), the sample used in the analysis contained 7520 observations on purchases of 7205 single packs and 315 single cigarette sticks over an 86-month period. Among these observed purchases, $6314(84 \%)$ were for licit brands and $1206(16 \%)$ were for illicit brands. Breakdowns of the observations in each survey wave by brand group and packaging type are reported in table 1 . Data management and statistical analysis were performed using STATA V.11.2. ${ }^{29}$

\section{RESULTS}

Cigarette purchases in violation of the inflation-adjusted 2011 minimum MYR7.00 per 20-stick pack price is reported for all survey waves by packaging type and brand group in table 2 . In wave $4,3.9 \%$ of licit cigarette purchases by ITC Malaysia Survey respondents were for less than the inflation-adjusted minimum price, a figure that decreased significantly to $1.8 \%$ of purchases after the MPL went into effect in wave $5(54.1 \%$ fewer purchases in violation, $p=0.002)$. In fact, the proportion of licit cigarettes that violated the inflation-adjusted MYR7.00 MPL declined in each subsequent survey wave (except from wave 2 to 3 ), decreasing from $18.8 \%$ in violation in wave 1 to the aforementioned $1.8 \%$ in wave 5 . When the MPL came into effect, just $1.8 \%$ of packs and $0.4 \%$ of single sticks among licit brands were in violation of the MPL. As one might expect, since the strategy of many illicit brands is selling at a price below licit brands (see web table 1), violation of the MPL was very high among illicit purchases, and prices stayed flat as the MPL went into effect in wave 5 (wave $489.8 \%$, wave $591.9 \% ; 2.3 \%$ more purchases in violation, $\mathrm{p}=0.496$ ). Further, violation of the MPL among all cigarette purchases in Malaysia did not significantly change (wave $415.4 \%$, wave $516.7 \%$; $8.4 \%$ more purchases in violation, $p=0.418$ ) between waves 4 and 5 . It should be noted that the proportion of illicit cigarettes had remained fairly constant from waves 1 to 3 before decreasing significantly $(\mathrm{p}<0.001)$ between waves 3 and 4 . The lack of a decrease in violations of the MPL is at least partially attributable to a $19.0 \%$ increase in the proportion of illicit purchases in our sample, from $13.4 \%$ in wave 4 to $16.5 \%$ in wave 5 (reported in table 1 , $\mathrm{p}=0.041)$.

Mean nominal and real prices for standardised 20-stick packs of licit and illicit cigarettes by packaging type for each survey wave are reported in web table 1 , while real prices are plotted in relation to the inflation-adjusted MYR7.00 MPL in figure 2. The mean real price of all licit cigarette purchases increased from MYR9.40 in wave 4 to MYR9.55 in wave 5, a statistically significant increase $(p=0.006)$. The mean inflation-adjusted price for licit cigarettes was MYR7.42 in wave 1 (2005), a figure well above the 2011 MYR7.00 MPL, an indicator of why so many licit cigarettes were compliant with the MPL both before and after its implementation. This finding contrasts with the mean real purchase price of illicit cigarettes, which did not 


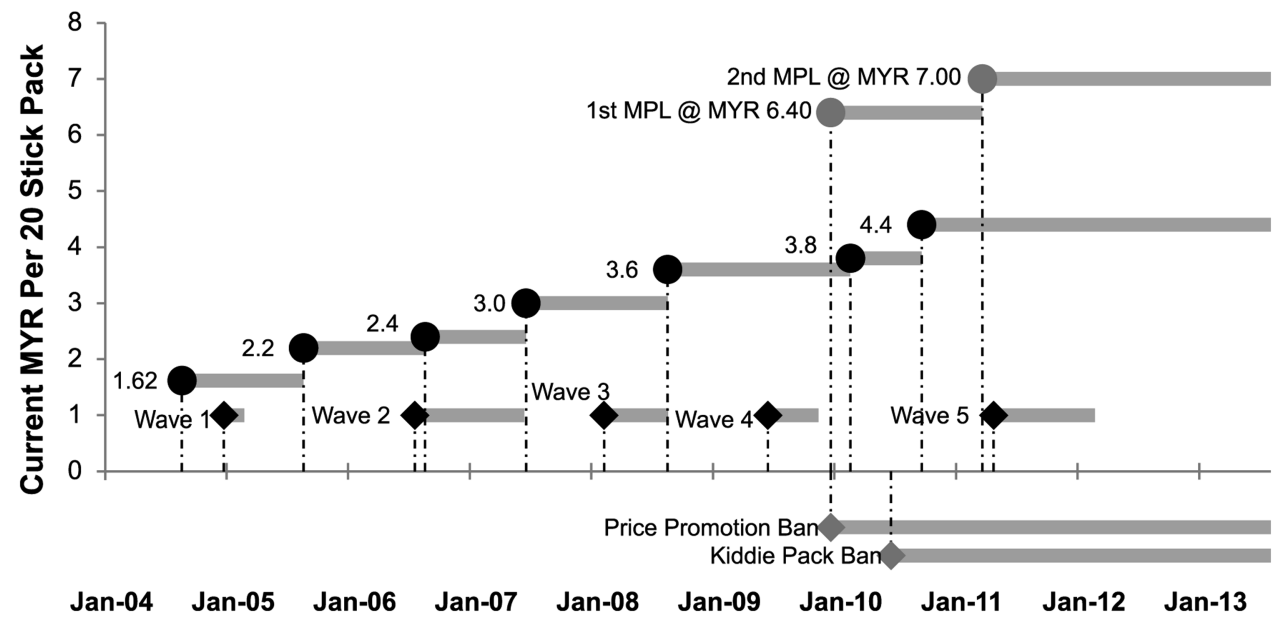

Figure 1 Timeline of specific excise tax levels, minimum price levels, ITC Survey waves, and other tobacco control policies implemented in Malaysia (2004-2013). ITC, International Tobacco Control; MPL, minimum price law.

significantly change from a recorded MYR4.57 in wave 4 to MYR4.23 in wave $5(\mathrm{p}=0.134)$.

When stratified by packaging type, the changes between waves 4 and 5 in rates of violation of the MPL as well as mean nominal and real prices are not materially different from the changes for all purchases in each brand type (tables 1 and 2, and web table 1). This result is most likely attributable to the much larger number of pack purchases outweighing the effects of single stick purchases in the study sample. Cigarettes sold as single sticks were equally likely to be an illicit brand as cigarettes sold by the pack (all $\mathrm{p}>0.05$ ). We performed similar comparisons of proportions and means tests for each study wave and its immediate precedent; the results are reported in tables 1 and 2, and web table 1 . In almost all waves and brand groups, ${ }^{i}$ for every measure of real and nominal price, and rate of violation of the minimum price level, cigarettes sold as single sticks were significantly more expensive and more likely to comply with the MPL than cigarettes sold by the pack.

\section{DISCUSSION}

We found that almost all licit cigarettes in Malaysia were purchased for an amount greater than the minimum price both before and majority of illicit cigarettes were sold below the minimum price both before and after the MPL was passed. The evidence from the ITC Survey indicates that the MPL in Malaysia probably did not have a substantial impact on the prices of cigarettes. Prices of licit cigarettes rose in line with excise tax increases between waves 4 and 5, that is, during the time when the MPL was adopted, while illicit cigarette prices remained flat. We hypothesise that any observed licit cigarette price increases were at least in part attributable to specific excise tax increases and not due to the MPL, given that most licit cigarettes were above the minimum price before the policy went into effect. Our study cannot directly address this hypothesis, and we believe that further research should be conducted.

iThe exceptions were Nominal Price for Illicit Brands in wave 1, $p=0.061$, Nominal Price for Illicit Brands in wave $3, p=0.311$, Real Price for Illicit Brands in wave $1, p=0.061$, and Real Price for Illicit Brands in wave $3, p=0.308$. after the MPL was passed. On the other hand, the overwhelming

The Malaysian MPL legislation has some features that can potentially contribute to positive public health outcomes, including nominal minimum price increases over time, which help to protect against inflation. ${ }^{10}$ The MPL, 'kiddie pack' ban and price promotion ban all aimed to raise the price of entry to the cigarette market, thereby reducing consumption among the most vulnerable populations. An MPL orders a private company to increase its margin on each sale of its least expensive products, with the higher profits resulting from the retail price increase being yielded to the tobacco industry. Any further MPLs that do not increase the retail prices of the majority of cigarettes will serve only to protect the market share of incumbent manufacturers. An MPL that is set below the offering price of incumbent manufacturers should have no effect on prices and cigarette consumption, unless a competitor seeks to undercut the rest of the market on price.

If MPLs are to improve public health, they must result in a price increase among all packaging and brand types, particularly

Table 1 Observations of all, licit and illicit brand cigarette purchases and proportion of purchases that were illicit

\begin{tabular}{|c|c|c|c|c|c|}
\hline $\begin{array}{l}\text { Number of } \\
\text { observations }\end{array}$ & $\begin{array}{l}\text { Wave } \\
1 \\
(2005)\end{array}$ & $\begin{array}{l}\text { Wave } 2 \\
(2006-2007)\end{array}$ & $\begin{array}{l}\text { Wave } \\
3 \\
(2008)\end{array}$ & $\begin{array}{l}\text { Wave } \\
4 \\
(2009)\end{array}$ & $\begin{array}{l}\text { Wave } 5 \\
(2011-2012)\end{array}$ \\
\hline All brands & 1652 & 1159 & 1459 & 1658 & 1592 \\
\hline Packs & 1587 & 1110 & 1412 & 1577 & 1519 \\
\hline Sticks & 65 & 49 & 47 & 81 & 73 \\
\hline Licit brands & 1407 & 935 & 1192 & 1451 & 1329 \\
\hline Packs & 1355 & 895 & 1153 & 1384 & 1267 \\
\hline Sticks & 52 & 40 & 39 & 67 & 62 \\
\hline Illicit brands & 245 & 224 & 267 & 207 & 263 \\
\hline Packs & 232 & 215 & 259 & 193 & 252 \\
\hline Sticks & 13 & 9 & 8 & 14 & 11 \\
\hline \multicolumn{6}{|c|}{ Proportion of purchases that were illicit } \\
\hline All & $15.4 \%$ & $19.7 \%$ * & $19.8 \%$ & $\begin{array}{l}13.4 \% \\
* * *\end{array}$ & $16.5 \%$ * \\
\hline Packs & $15.3 \%$ & $19.8 \%$ * & $19.7 \%$ & $\begin{array}{l}13.4 \% \\
* * *\end{array}$ & $16.6 \%$ * \\
\hline Sticks & $19.4 \%$ & $16.4 \%$ & $22.9 \%$ & $11.9 \%$ & $12.9 \%$ \\
\hline
\end{tabular}

Liber AC, et al. Tob Control 2015;24:iii83-iii87. doi:10.1136/tobaccocontrol-2014-052028 
Table 2 Proportion of all, licit and illicit brands cigarette purchases in violation of the 2011 minimum price level of MYR7.00 in 2011 prices

\begin{tabular}{llllll}
\hline In violation of 2011 minimum price & Wave 1 (2005), \% & Wave 2 (2006-2007), \% & Wave 3 (2008), \% & Wave 4 (2009), \% & Wave 5 (2011-2012), \% \\
\hline All brands & 27.7 & 28.1 & 28.4 & $15.4^{* * *}$ & 16.7 \\
Pack & 27.8 & 28.5 & 28.5 & $15.6^{* * *}$ & 16.9 \\
Stick & 21.5 & $5.1^{*}$ & 18.9 & 4.6 & 2.0 \\
All licit brands & 18.8 & $13.0^{* *}$ & 11.7 & $3.9^{* * *}$ & $1.8^{* *}$ \\
Pack & 19.0 & $13.2^{* *}$ & 11.8 & $4.0^{* * *}$ & $1.8^{* *}$ \\
Stick & 7.2 & 3.3 & 0.0 & 0.0 & 0.4 \\
All illicit brands & 76.9 & $89.7^{* *}$ & $96.3^{* *}$ & $89.8^{*}$ & 91.9 \\
\hline
\end{tabular}

${ }^{*} \mathrm{p}<0.05,{ }^{* *} \mathrm{p}<0.01,{ }^{* * *} \mathrm{p}<0.001$ indicates the test of comparisons of proportions result. The degree of violation of the minimum price law (MPL) was tested against the immediately preceding wave. MPL violation is determined based on inflation-adjusted 2011 prices. Illicit brands are not disaggregated by packaging type due to the low number of illicit brand purchases by single sticks that were observed during the study $(n=55)$.

among the least expensive brands in a market. This was not observed in the present study of the Malaysian MPL, but other versions of MPLs that are set at levels that are higher than existent economy brands could begin to achieve this objective. As an alternative to using an MPL, continuously increasing uniform specific excise taxes at a pace above that of inflation and income growth is still the most effective method to raise the prices of the least expensive cigarettes on the market. ${ }^{19}{ }^{30}$ Substantially raising specific excise taxes is a proven strategy to raise the prices of all cigarettes, and in doing so, raise revenue for the government.

The effectiveness of the Malaysian MPL is intrinsically tied to the availability of cheap illicit cigarettes. Many smokers in our sample reported purchasing illicit cigarette brands at prices far below the statutory minimum level. More than half of the illicit cigarette purchases observed in the ITC Survey data were for kreteks produced in Indonesia, most notably the Gudang Garam brand. These kreteks are reported to be smuggled across the long land and sea borders that Malaysia shares with Indonesia, a country with very low tobacco taxes and few strong tobacco control laws. $^{26} 2731$ The enforcement of the MPL falls to the Malaysia Ministry of Health, which is conducting periodic retailer compliance checks under the codename Ops Basub (in English, Operation Wash Out). ${ }^{32}$ Newspaper articles occasionally write about hundreds of vendors being caught selling cigarettes for less than the minimum price, but (in the knowledge of the authors) journalists have not engaged in a systematic analysis of whether these enforcement measures have made retailers less likely to violate the MPL. ${ }^{33}$ The Malaysian MPL will not be fully functional until there are substantially fewer illicit cigarettes being sold in the country, something the Malaysian government could do by implementing the policies called for in the Protocol to Eliminate Illicit Trade in Tobacco Products of the WHO FCTC.

\section{LIMITATIONS}

This analysis could not separate the effect of the MPL from the effects of an excise tax increase and the bans on 'kiddie' packs and price promotions because all these policies went into effect between waves 4 and 5 . We do not possess the ideal data to observe the difference in prices offered to consumers in the period between the last tax increase in October 2010 and after the MYR7.00 MPL came into effect in April 2011. Having this ideal data would have allowed us to definitively rule out the possibility that the MPL increased prices. Nevertheless, our data indicate that any discovered effect would certainly be small. We also could not evaluate separately the impact of establishing the minimum price from raising the minimum price level, since both of these events occurred between waves 4 and 5. Further, we cannot directly observe how the tobacco industry, retailers or distributors responded to the MPL or tax increases because our data describe the behaviour of consumers alone. Further, because we rely on consumers to self-report their purchase prices, our data are subject to recall bias, rounding and other accidental misrepresentations of consumerreported purchase prices. Still, on the whole self-reported prices are known to be a valid measure of the actual prices that smokers face in the retail environment. ${ }^{34}$ We used a single characteristic, brand, to determine whether a cigarette was illicit, leading to a possible underestimation of the total number of illicit cigarette purchases than would have been found if we included multiple indicators of an illicit purchase, including vendor type and the presence of a legitimate tax stamp on a smoker's cigarette pack. Even taking into account these shortcomings, the data presented here indicate that the impact of the MPL on cigarette prices in Malaysia has been minimal.
Figure 2 Real prices and values per 20-stick packs of licit and illicit brands by packaging type and minimum price law (MPL; 2011 MYR7.00).

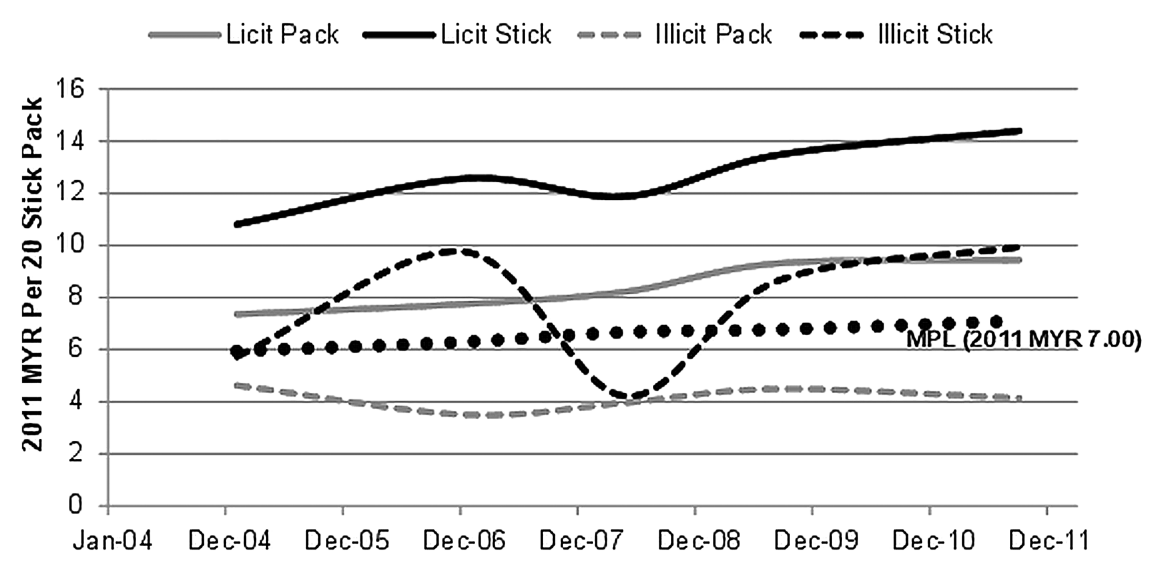

Liber AC, et al. Tob Control 2015;24:iii83-iii87. doi:10.1136/tobaccocontrol-2014-052028 


\section{CONCLUSIONS}

This evaluation of the Malaysian MPL can inform policymaking in Malaysia and other jurisdictions that are considering adopting or improving their use of a cigarette MPL. The continued availability of cheap, illicit cigarette brands in the Malaysian market is undermining the goals of the MPL. Because the proportion of illicit cigarettes purchased rose by $19.0 \%$ as the MPL came into effect, the Malaysian MPL was unable to decrease access to cheap cigarettes as stakeholders might have intended. More importantly, we found evidence that the Malaysian minimum price level appears to have been set too low to noticeably affect the prices of licit cigarette brands. Setting the minimum price level much higher than has been done in the past would be more likely to raise market prices and have a positive impact on public health, as would the continued use of the proven policy of increasing uniform specific tobacco excise taxes in order to reliably increase tobacco product prices, and decrease tobacco consumption, disease and death.

\section{What this paper adds}

- Minimum price laws for cigarettes have been proposed to be potential non-tax policies that can raise cigarette prices and benefit public health.

- No prior study has examined the impact of Malaysia's minimum price law on the prices smokers paid for their cigarettes.

- The Malaysian minimum price law appears to have had only a minimal impact on cigarette prices because it was undermined by the presence of cheap illicit cigarettes and a minimum price level that was set too low to raise the prices of licit cigarettes.

\section{Twitter Follow Alex Liber at @AlexCLiber}

Acknowledgements The authors would like to thank Anne Chiew Kin Quah and Jeffrey Drope for their valuable comments and support during the study. They would like to thank John Daniel for his keen editing work on the manuscript.

Contributors $\mathrm{ACL}$ conceived of the study's design, prepared the data, performed the data analysis and wrote the initial draft of the manuscript. HR, MO and FJC helped design the data analysis, aided in the data interpretation, and helped edit and prepare the final manuscript. ACL is the ultimate guarantor of the content.

Funding The data collection for the ITC Malaysia Project is supported by grants R01 CA100362 and P50 CA111236 (Roswell Park Transdisciplinary Tobacco Use Research Center), P01 CA138389 and R01 CA090955 from the National Cancer Institute of the USA, Robert Wood Johnson Foundation (045734), Canadian Institutes of Health Research (79551 and 115016) and the Malaysian Ministry of Health.

Competing interests None declared.

Patient consent Obtained.

Ethics approval The ITC Malaysia Survey was cleared for ethics by the Research Ethics Committee (Human), Universiti Sains Malaysia, at the Clinical Science Research Platform Office, Universiti Sains Malaysia, Kubang Kerian, Kelantan, Malaysia; the Office of Research Ethics, University of Waterloo, Ontario, Canada; and Human Research Ethics Committee, The Cancer Council Victoria, Melbourne, Australia.

Provenance and peer review Not commissioned; externally peer reviewed.

Data sharing statement The data used for this study are available on request from the ITC Project at the University of Waterloo, Ontario, Canada.

\section{REFERENCES}

1 Chaloupka FJ, Straif K, Leon ME. Effectiveness of tax and price policies in tobacco control. Tob Control 2011;20:235-8.
2 Chaloupka F, Warner K. Section 2.4: econometric studies of the demand for other tobacco products. In: Economics of smoking. U.S. Department of Health and Human Services, 2000. http://tigger.uic.edu/ fjc/Presentations/Papers/handfinal.pdf (accessed 13 Jun 2011).

3 Asaria P, Chisholm D, Mathers C, et al. Chronic disease prevention: health effects and financial costs of strategies to reduce salt intake and control tobacco use. Lancet 2007;370:2044-53.

4 Fichtenberg CM, Glantz SA. Association of the California Tobacco Control Program with declines in cigarette consumption and mortality from heart disease. $N$ Engl J Med 2000:343:1772-7.

5 Henriksen L. Comprehensive tobacco marketing restrictions: promotion, packaging, price and place. Tob Control 2012;21:147-53.

6 IARC. Effectiveness of price and tax policies for control of tobacco. Lyon, France: International Agency for Research on Cancer, 2011.

7 Feighery EC, Ribisl KM, Schleicher NC, et al. How do minimum cigarette price laws affect cigarette prices at the retail level? Tob Control 2005;14:80-5.

8 Chaloupka FJ. Commentary on Ross et al. (2011): beyond cigarette taxes-the need for research on other cigarette pricing policies. Addiction 2011;106: $620-1$.

9 Albuja S, Daynard RA. The Framework Convention on Tobacco Control (FCTC) and the adoption of domestic tobacco control policies: the Ecuadorian experience. Tob Control 2009:18:18-21.

10 Lai DSLT. Food Act 1983: Control of Tobacco Product (Amendment) (No. 2) Regulations 2009. 2010. http://bit.ly/1g37QQa (accessed 30 Jul 2013).

11 Lai DSLT. Control of Tobacco Product (Amendment) Regulations 2011. 2011. http:// bit.ly/1on3Ex1 (accessed 10 Jul 2014).

12 Chieh YH. Respect minimum price, say cigarette makers. Malays. Insid. 2011. http:// www.themalaysianinsider.com/malaysia/article/ respect-minimum-price-say-cigarette-makers (accessed 21 Nov 2014).

$13 \mathrm{Ng} \mathrm{M}$, Freeman MK, Fleming TD, et al. Smoking prevalence and cigarette consumption in 187 countries, 1980-2012. JAMA 2014;311:183-92.

14 Guindon GE, Driezen P, Chaloupka FJ, et al. Cigarette tax avoidance and evasion: findings from the International Tobacco Control Policy Evaluation Project. Tob Control 2014;23:i13-i22.

15 Eriksen M, Mackay J, Ross H. The tobacco atlas. American Cancer Society, 2012.

16 Euromonitor International. Tobacco in Malaysia. 2013.

17 ERC Group. World Cigarette Reports 2010. Suffolk, UK: ERC Group Ltd, 2010.

18 SEATCA. ASEAN Tobacco Tax Report Card: regional components and trends. 2013. http://bit.ly/1dd3PoW (accessed 30 Jul 2013).

19 Blecher EH, Van Walbeek CP. Cigarette affordability trends: an update and some methodological comments. Tob Control 2009;18:167-75.

20 Economist Intelligence Unit. Worldwide Cost of Living Survey. 2013.

21 World Bank. World Development Indicators. 2014. http://data.worldbank.org/ indicator (accessed 17 Apr 2014).

22 Yong $\mathrm{HH}$, Borland R, Hammond D, et al. Levels and correlates of awareness of tobacco promotional activities among adult smokers in Malaysia and Thailand: findings from the International Tobacco Control Southeast Asia (ITC-SEA) Survey Tob Control 2008:17:46-52.

23 ITC Project. ITC Malaysia National Report. Findings from wave 1 to 4 surveys (2005-2009)., Waterloo, Ontario, Canada: University of Waterloo; Pulau Pinang, Malaysia: Universiti Sains Malaysia; and Putrajaya, Malaysia: Ministry of Health, 2012. http://bit.ly/1dravn5 (accessed 23 Aug 2013).

24 ITC Project. International Tobacco Control Southeast Asia Survey Wave 5: ITC SEA Technical Report. 2013. http://itc.media-doc.com/files/SEA5-TR-March_2013-FINAL. pdf (accessed 31 Jan 2014).

25 Bank Negara Malaysia. 3.5.8 Consumer Price Index: Monthly Statistical Bulletin, July 2012. 2012. http://www.bnm.gov.my/index.php?ch=en_publication_catalogue\&pg=en_ publication_msb\&eld=box $1 \& m$ th $=7 \& y r=2012 \&$ lang=en (accessed 28 Aug 2014).

26 Awang $\mathrm{R}$, Omar M. Determining the extent and nature of illicit cigarette use in Malaysia involving pack collection and interview: findings from the wave 4 ITC study. 2012. http://bit.ly/1dkRKI9 (accessed 26 Aug 2013).

27 CMTM. Illicit cigarettes study in Malaysia: year 2010. 2011

28 Shang C, Chaloupka FJ, Zahra N, et al. The distribution of cigarette prices under different tax structures: findings from the International Tobacco Control Policy Evaluation (ITC) Project. Tob Control 2014;23:i23-9.

29 Stata Corp. STATA. College Station, TX: Stata Corp, 2011

30 WHO. WHO technical manual on tobacco tax administration. Geneva, Switzerland World Health Organization, 2010. http://bit.ly/KmkoYi (accessed 22 Mar 2011).

31 WHO. Tobacco control country profiles. World Health Organisation, 2012. http://www. who.int/tobacco/surveillance/policy/country_profile/en/index.html (accessed 9 Oct 2012).

32 Abdullah NHB. Enforcement Regulations of Tobacco Control 2004 Series 2/2013 "Operation Wash out II." Malays. Minist. Health. 2013. http://www.moh.gov.my/ press_releases/376 (accessed 23 Aug 2013).

33 Sivanandam H. Contraband cigarettes sellers may have licence revoked. Sun Dly 2012. http://www.thesundaily.my/news/263082q (accessed 23 Aug 2013).

34 Chaloupka FJ, Tauras JA, Strasser JH, et al. A comparison of alternative methods for measuring cigarette prices. Tob Control 2015;24:269-74. 